\title{
The great help of a virus in the fight against bacteria!
}

\author{
Michel Jadoul ${ }^{1} \cdot$ Laura Labriola $^{1}$
}

Accepted: 23 February 2021 / Published online: 8 March 2021

(c) Italian Society of Nephrology 2021

Vascular access remains the Achilles' heel of hemodialysis (HD), and a functional arteriovenous fistula (AVF), a concept invented by American physicians of Italian descent in the early sixties, can not be created in all HD patients. Thus, the use of HD catheters, despite the multiple associated risks $[1,2]$, especially catheter-related blood stream infections (CRBSIs), is unavoidable.

Although CRBSI rates have somewhat improved over the last decades, both in HD patients and in ICU patients [3], CRBSIs remain a significant cause of morbidity and mortality. The key steps to preventing CRBSIs include firstly minimizing the use of catheters, and secondly applying consistently stringent hygienic precautions in catheter care, especially the disinfection of the hub, that may act otherwise as the open door to bloodstream invasion by bacteria [4].

Despite more than 150 years of converging evidence supporting hygienic precautions, starting with Semmelweiss and the importance of handwashing, in the current modern, busy world, hygienic precautions are too often inconsistently followed in various health care settings, including in HD units [2-4]. In that context, the report by Heidempergher et al. in this issue of the Journal of Nephrology is refreshing [5]. The authors studied CRBSI rates in 2 HD units in Milan, both during the 2 years prior to, and then during the first wave (February to May 2020) of the COVID-19 pandemic. Even considering that the CRBSI rate was relatively good [2] during the whole of 2019, and did not change compared with 2018 , the rate decreased sharply and rapidly as soon as hygienic precautions were dramatically reinforced from the start of the COVID-19 pandemic. Indeed, the CRBSI rate decreased by $83 \%$ as compared with 2019 [IRR 0.17 (95\% CI 0.004-1.009) $\mathrm{p}=0.03$ ]. Moreover, the observed reduction was even more striking [IRR 0.09 (95\% CI $0.002-0.64) \mathrm{p}=0.004]$ in comparison with the same period

Michel Jadoul

michel.jadoul@uclouvain.be

1 Cliniques Universitaires Saint-Luc, Université catholique de Louvain, Avenue Hippocrate 10, 1200 Brussels, Belgium
(February-May) of 2019. The authors conclude that stricter implementation of hygienic precautions in the dialysis setting can markedly improve the problem of CVC-related infections.

Overall, the authors' findings warrant a few comments. First, the initial (2018-2019) CRBSI rates were good but not excellent [2], thus leaving room for improvement. Second, the sharp decrease in CRBSI rates may partly result from the fact that both participating units moved to the systematic use of a hydroalcoholic solution (HAS) at the start of the COVID-19 first wave. It should be stressed that HAS use is known to favor the actual application of hygienic precautions as compared with handwashing with water and soap. The latter can indeed hardly be performed 15 to 25 times a day, without some skin reactions such as drying etc. Third, although one unit switched from unfractionated heparin to a citrate $46.7 \%$ lock solution in January 2020 , whereas the other unit was already using citrate $46.7 \%$ in 2019 , this change seems unlikely to account for the better CRBSI rates in 2020 for two reasons: (i) even the unit using citrate as a lock solution in both 2019 and 2020 obtained a drastic reduction in both CRBSIs and exit-site infections (ESIs) [1.85 (0.75-3.84) in February-May 2019 versus 0 CRBSIs per 1000 catheter-days during the same period in 2020 $(\mathrm{p}=0.02)$, and $1.54(0.56-3.41)$ versus $0.73(0.12-2.4)$ ESIs per 1000 catheter-days, respectively; (ii) a meta-analysis including 13 RCTs comparing citrate (with or without antimicrobial agents) versus heparin locks did not demonstrate that high concentrations of citrate alone are beneficial in the prevention of CRBSIs as compared with heparin locks [6].

As Heidempergher et al. rightly emphasize, hygienic standards have never been so stringent. Motivated by the fear of being infected with SARS-CoV-2 and of being implicated in the spread of SARS-CoV-2 infection to HD patients and colleagues, it is very likely that health care workers paid more attention to respecting hygiene rules for catheter care. Beathard et al. also obtained a dramatic reduction of CRBSI rates simply by strictly respecting the hygiene precautions for HD tunneled catheters [2]. Along the same line, a rapid and significant decrease in CRBSI rates with temporary 
catheters was documented in 103 ICUs in the U.S. after the implementation of the study intervention, i.e. basic aseptic procedures for catheter insertion and care, and was maintained throughout the 18-month follow up [3]. Similarly, intensive staff training regarding strict observance of aseptic techniques in the buttonhole procedure for cannulation of AVFs allowed to largely mitigate the risk of AVF-associated infections in our busy, in-center HD unit.

Overall, despite the limitations of the A-B (or before after) observational study design, the authors make a convincing case for the fact that COVID-19 helped reduce CRBSI rates dramatically. This is good news for those of us who are coping with this unprecedented once-in-a-lifetime event and who did not experience the Spanish Flu crisis a century ago.

Good news may not come alone! It will thus be intriguing to observe whether other unexpected (of course initially not desired) benefits are reported as a result of the current crisis. Indeed, improved adherence to hygienic precautions-such as hand hygiene and contact precautions - might be expected to reduce the transmission of multi-resistant bacteria [7] and blood-borne viruses such as HCV and HBV [8], all of which remain prevalent in HD units globally.

In conclusion, the work by Heidempergher et al. nicely reminds us that times of crisis are also times of opportunity. Knowledge alone is frequently not enough to achieve basic quality targets such as the prevention of CRBSIs in hemodialysis. The willingness to change, together with the fear of being infected with SARS-CoV-2 and of being responsible for transmission to patients and colleagues, have driven a remarkably rapid change of behavior, leading to a dramatic reduction in CRBSIs, the most devastating complication of dialysis catheter use. In the absence (hopefully) of such a crisis in the near future, the crucial role of strong leadership by dialysis unit medical directors and head nurses can not be overemphasized if quality targets are to be reached. If the leaders of the unit do not make excellent hygienic precautions a high priority, consistent implementation of hygienic protocols will not be obtained. Conversely, by no means should the implementation of alternative prophylactic preventive techniques or strategies be used as an excuse to relax the application of basic but crucial hygiene procedures [9].
Ethical approval This editorial does not contain any unpublished studies in human participants or animals performed by any of the authors.

Informed consent There is no question of informed consent for this editorial, that reviews published studies.

\section{References}

1. Labriola L, Seront B, Crott R, Borceux P, Hammer F, Jadoul M (2018) Superior vena cava stenosis in haemodialysis patients with a tunnelled cuffed catheter: prevalence and risk factors. Nephrol Dial Transplant 33:2227-2233. https://doi.org/10.1093/ndt/gfy15

2. Beathard GA, Urbanes A (2008) Infection associated with tunneled hemodialysis catheters. Sem Dial 21:528-538. https://doi. org/10.1111/j.1525-139X.2008.00497.X

3. Pronovost P, Needham D, Berenholtz S, Sinopoli D, Chu H, Cosgrove S, Sexton B, Hyzy R, Welsh R, Roth G, Bander J, Kepros J, Goeschel C (2006) An intervention to decrease catheter-related bloodstream infections in the ICU. N Engl J Med 355:2725-2732. https://doi.org/10.1056/NEJMoa061115

4. Rosemblum A, Wang W, Ball LK, Latham C, Maddux FW, Lacson E Jr (2014) Hemodialysis catheter care strategies: a clusterrandomized quality improvement initiative. Am J Kidney Dis 63:259-267. https://doi.org/10.1053/j.ajkd.2013.08.019

5. Heidempergher M, Sabiu G, Orani MA, Tripepi G, Gallieni M (2021) Targeting COVID-19 prevention in hemodialysis facilities is associated with a drastic reduction in central venous catheterrelated infections. J Nephrol. https://doi.org/10.1007/s40620-02000900-3 [Online ahead of print]

6. Zhao Y, Li Z, Zhang L (2014) Citrate versus heparin lock for hemodialysis catheters: a systematic review and meta-analysis of randomized controlled trials. Am J Kidney Dis 63:479-490. https ://doi.org/10.1053/j.ajkd.2013.08.016

7. Midturi JK, Ranganath S (2019) Prevention and treatment of multidrug-resistant organisms in end-stage renal disease. Adv Chronic Kidney Dis 26:51-60. https://doi.org/10.1053/j.ackd.2018.09.003

8. Labriola L, Jadoul M (2010) The decades-long fight against HBV transmission to dialysis patients: slow but definite progress. Nephrol Dial Transplant 25:2047-2049. https://doi.org/10.1093/ndt/ gfq238

9. Labriola L, Pochet JM (2017) Any use for alternative lock solutions in the prevention of catheter-related blood stream infections? J Vasc Access 18:34-38. https://doi.org/10.5301/jva.5000681

Publisher's Note Springer Nature remains neutral with regard to jurisdictional claims in published maps and institutional affiliations.

\section{Compliance with ethical standards}

Conflict of interest The authors do not have any conflict of interest to declare. 